\title{
New Consumer Guidance on Wearable Devices from the Consumer Electronics Show 2020
}

\author{
An Expert Interview with Nassir F Marrouche
}

Cardiac Electrophysiology, Tulane University School of Medicine, New Orleans, LA, USA

DOl: https://doi.org/10.17925/HI.2020.14.1.9

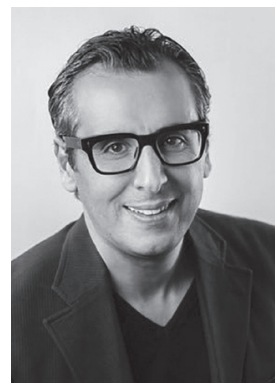

\section{Nassir Marrouche}

Dr Nassir Marrouche is a prominent electrophysiologist and Director of the Cardiac Electrophysiology Division of Tulane University Medical School. He has published over 200 peer-reviewed papers, with a focus on atrial fibrillation and regularly presents at a range of meetings internationally. In addition, he is Course Director of the Western Atrial Fibrillation Symposium, which took place on 28-29 February 2020 and aims to further the research of education on atrial fibrillation, create connections and encourage development and innovation for professionals dealing with atrial fibrillation in a multitude of settings.

\section{Keywords}

Wearable devices, consumer guidance Consumer Electronics Show (CES) 2020, Consumer Technology Association (CTA), Heart Rhythm Society (HRS), health solutions, wearables

Disclosures: Nassir Marrouche has no financial or non-financial relationships or activities to declare in relation to this article.

Review Process: This is an expert interview and as such, has not undergone the journal's standard peer-review process.

Compliance with Ethics: This article is an interview and did not involve any studies with human or animal subjects performed by the author.

Authorship: The named author meets the International Committee of Medical Journal Editors (ICMJE) criteria for authorship of this manuscript, takes responsibility for the integrity of the work as a whole, and has given final approval for the version to be published.

Access: This article is freely accessible at

touchCARDIO.com (C) Touch Medical Media 2020.

Received: 22 January 2020

Accepted: 5 February 2020

Published Online: 12 March 2020

Citation: Heart International. 2020;14(1):9-10

Corresponding Author: Nassir F Marrouche

1430 Tulane Avenue, SL-48, New Orleans, LA 70112, USA. E: nmarrouche@tulane.edu

Support: No funding was received for the publication of this article.
T current landscape of wearable technology is one of the most exciting and rapidly changing fields in medicine, especially for the general consumer. ${ }^{1}$ The potential of capturing a wider and deeper range of personal health information is vast, allowing for changes in care to a more personalised approach across all therapy areas. Cardiology, in particular, is ripe ground for emerging technology, with mobile electrocardiograms, activity tracking and blood-pressure monitors now being included on many mainstream devices. Consumer interest in health tracking is continuing to rise, with increasing numbers of consumers wishing to monitor their blood pressure and stress, alongside heart health and blood sugar levels.

In this expert interview, Dr Nassir Marrouche introduces the new joint-issued consumer guidance on wearable devices from the consumer Technology Association (CTA) and the Heart Rhythm Society (HRS), presented at the Consumer Electronics Show 2020, 7-10 January, Las Vegas, NV, USA. ${ }^{2}$

\section{Q. What is the current landscape for wearables and what do you think are the future possibilities for this area of technology in medicine?}

Digital health is changing lives for the better - providing more personalised care, delivering better outcomes and lowering costs. Wearable solutions are one of the fastest growing sectors in technology, and as more consumers capture personal health information, a cross industry-created guidance document has never been more important to provide clarity on the potential health and wellness benefits of wearables.

\section{Q. What are the benefits of these advances in digital health and how do you think they will change the future of healthcare?} Chronic diseases are increasing in prevalence and wearables help people monitor their health to aid in earlier diagnosis and better management of their conditions; furthermore, they provide information to the user that fosters a healthier lifestyle.

\section{Q. What is the background and rationale for the new Consumer Technology Association/Heart Rhythm Society consumer guidance on wearable devices, presented at the Consumer Electronics Show 2020?}

The pace of innovation with wearable technology is happening quickly and the intersection with health is providing new solutions for chronic disease management, as well as empowering consumers to know more about their personal health. As a result, there was a demand for consumer guidance on the use of this new area of technology that is supported by recommendations from 
both innovators in technology but also medical experts. In this joint consumer guidance from both the CTA and the HRS, the authors have provided recommendations that were simple yet impactful in controlling your health, focusing on prevention, knowing your data and setting goals. ${ }^{2}$ The recommendations represent the consensus of a group of experts with diverse expertise and perspectives.

Q. What is the aim for the Consumer Technology Association/Heart Rhythm Society consumer guidance on wearable devices?

In this document, we aimed to highlight this new intersection between consumer technology and health. We want people to be aware of what these wearables have to offer, how they can increase knowledge about one's health and how clinicians are optimistic about the data wearables can deliver.

\section{Q. What is the main advice for consumers and healthcare practitioners from this document?}

Key takeaways include how individuals can participate in their own health with wearables, how they can best manage the data provided and how to share data with their clinician, considerations when purchasing wearables, pros and cons; plus, we address frequently asked questions. $\square$

Valencell. National wearables survey reveals accelerating convergence of consumer wearables and personal health \& medical devices. 2018. Available at: https://valencell.com/press/2018/11/nationalwearables-survey-reveals-accelerating-convergence-of-consumer-wearables-and-personal-health-medical-devices/ (accessed 24 January 2020)

2. Consumer Technology Association, Heart Rhythm Society. Guidance for wearable health solutions. 2020. Available at: www.hrsonline.org/documents/CTA-Guidance-for-Wearable-Health-Solutions/download (accessed 24 January 2020). 